\title{
Sport Injuries in Karate Kyokushin Athletes
}

\author{
Laura Piejko*1,2, Dariusz Mosler ${ }^{3}$ and Natalia Grzebisz ${ }^{4}$ \\ ${ }^{1}$ Physiotherapy Faculty, J Kukuczka Academy of Physical Education, Poland \\ ${ }^{2}$ Medical Faculty, GWSH School of Economics, Poland \\ ${ }^{3}$ Institute Physical Education, Poland \\ ${ }^{4}$ Faculty of Dietetics, Poland
}

*Corresponding author: Laura Piejko, Physiotherapy Faculty, Medical Faculty, J Kukuczka Academy of Physical Education, GWSH

School of Economics, Poland

\section{ARTICLE INFO \\ Received: 崴 February 03, 2019 \\ Published: February 25, 2019}

Citation: Laura P, Dariusz M, Natalia G. Sport Injuries in Karate Kyokushin Athletes. Biomed J Sci \& Tech Res 15(1)-2019. BJSTR. MS.ID.002653.

Keywords: Athletic Injuries; Combat Sport; Martial Arts; Karate; Karate Kyokushin
ABSTRACT

Background: Karate training despite of the many positive aspects also carries the risk of accidents and injuries especially when taking part in organized training for competition and winning. The aim of the study was to evaluate the traumatic body injuries of female and male athletes participating in Kyokushin Karate European Cup in 2015 and XLIV Polish Karate Kyokushin Championships in 2017.

Material and Methods: The questionnaire survey was conducted among 61 elite karate kyokushin athletes competing in Polish and European tournament divided into two groups. The first group consisted of 40 males and the second group consisted of 21 female athletes. Respondents completing the survey were asked to answer questions about the training experience, stage, severity of the trainee, frequency of other exercises, using protectors to avoid the injury, frequently recurring injuries, how many times during training or competition a particular part of the body was injured and about serious or permanent damage.

Results: The common injuries were: contusions (91\%) and joint injuries (49\%) related to the left foot (23\%) and right hand (19\%). There was not statistically significant difference in the types of injuries between study groups except of joint injuries of the left foot $(\mathrm{p}=0.002)$ and back injuries ( $\mathrm{p}=0.017)$.

Conclusion: Males suffers injuries than women. Hands and feet are the most vulnerable part susceptible to injuries from karate kyokushin fighters. Most of athletes are willing to use protection of central parts and striking surfaces. Women athletes are slightly more prone to use protective equipment than male athletes.

\section{Introduction}

\section{Background}

Over the last several years the martial arts became an increasingly popular activity and benefited people of all ages. They can lower level of aggression, improve self-reliance, self-discipline and improve physical body [1], for example: cardio-respiratory and musculoskeletal systems, body composition [2,3]. Instead of positive profits, each of martial art style has many risks such as accidents and injuries. The risk of experience variable injuries is dependent on a style (technical aspects of each style), hours of training and a degree of competitiveness [1,4]. In karate style injuries are mostly associated with the karate striking surfaces for both sides- hands and feet and therefore they can be often damaged by attacking and other body parts can be damaged because of receiving a hit. In the past, karate competition was without any safety equipment. Doctrine of kyokushin style was to be hard and tough, so there was no protection equipment. In traditional form of kumite (karate competition), attacks to the head were prohibited and punishable even with disqualifications. Nowadays, to meet modern criteria of combat sports, protection gear is used. 
It differs to certain tournaments and mastery levels which comes along with rank of a games. Allowance of protection also changes traditional rules, so attacking to a head is allowed now. This is crucial to quantitative analysis of the strikes, as head is mostly accessible by roundhouse kick and other type of high kicks. Common protection for such strikes is to protect head with forearms. But in some cases, striking feet may accidentally hit the elbow, when opponents try to protect himself, when kick trajectory is badly set. Foots are also vulnerable while performing low kicks, as opponents try to block with their shins and knees. Badly executed technique or bad aiming may also lead to injury of attacker instead of delivering damages to an opponent. In case of fists, hits also are blocked (still, hitting a face with hands are prohibited in this style). Protecting with forearms, especially elbows are may cause more damage to attacker than for blocker. Moreover, successful, powerful strikes may deliver severe damages to opponent when hits are constructive.

For that purpose, protection gear for hands, shin and foots, head and teeth and suspensor are allowed. But their use is not obligatory, and some of athletes tends to not use it as from subjective feeling they affect a movement or simply they believe that use of such equipment are not the way of this martial art. Usage of such equipment differs among athletes. Central organs such head or genitalia are more sensitive, and athletes are more prone to use protection for that areas, but choice of distal parts protection varies. Exact distribution of injuries with or without such equipment through an athlete carrier is not fully studied yet. Moreover, collision injury is one of possible type, but there are also injuries that comes with overuse of body part as accumulated damages to ligaments which may led to torsion or backpain. Strikes requires lot of full body rotation, so there is considerable torque applied to spine ligaments each times they strike. In bad circumstances, when overload accumulates and because of counterforce of opponent workload for back's ligaments are to severe, it may lead to an injury or in light circumstanced to lower back pain for sometimes in case of only some torsion or microdamage. Finally, the aim of this study was to analyze the injuries occurring in top elite karate kyokushin athletes. From premises presented above, which describes circumstances of injuries and possible severity of damages, following hypothesis were formed:

a. Most of athletes are willing to use protection of central parts (breast, suspensors).

b. Women athletes are more prone to use protective equipment than male athletes.

c. Injuries were more frequent among distal part of a body than central ones.

d. Males suffers more injuries than a woman.

\section{Material and Methods}

Questionnaire survey designed by the authors was conducted amongst the group of 61 people participating in Kyokushin
Karate European Cup in 2015 and XLIV Polish Karate Kyokushin Championships in 2017 selected randomly. The inclusion criteria for the study were: regular participation in karate training, at least three years of competition and consent to participate in the study. Exclusion criteria were: lack of consent to participate in the study, irregular participation in karate trainings and too short training experience (less than three years of competition). Then the 61 athletes were divided into 2 groups. The first group consisted of 40 males and the second consisted of 21 females. The largest group were athletes with black belts- $82 \%$ and brown belts $18 \%$.

Among males, the mean age of was $23 \pm 4$ years (18-34), mean weight of $77 \pm 2 \mathrm{~kg}$ (64-100), mean body height of $181 \pm 6 \mathrm{~cm}$ (172195). 36 individuals showed right laterality of the upper and lower limbs, ambidexterity was declared by 4 people. Among the male group the mean of training experience was $10,8 \pm 3$ years.

These athletes practiced karate approximately for 5 times per week, additionally they practiced another kind of physical activity for more than 3 times per week. Among females in turn, the mean age of was $22 \pm 3$ years (20-31), mean weight of was $63 \pm 7 \mathrm{~kg}$ (5180 ), mean body height of was $168 \pm 5 \mathrm{~cm}$ (157-175). 19 females showed right laterality of the upper limbs, left one - remaining 2 females. Prevailing right laterality of the lower limbs (18 females), while left and right laterality of the lower limbs declared 3 of them. The mean of training experience was $11,8 \pm 3$ years. These athletes practiced karate approximately for 5 times per week. Also they practiced other physical activities for almost 4 times per week. Characteristics of the study groups are presented in Table 1.

Table 1: Characteristics of the study groups: number $(\mathrm{N})$, age, body weight, body height (mean, standard deviation, minimummaximum range).

\begin{tabular}{|c|c|c|c|c|}
\hline Groups & $\mathbf{N}$ & Age [years] & $\begin{array}{c}\text { Body height } \\
\text { [cm] }\end{array}$ & $\begin{array}{c}\text { Body } \\
\text { weight [kg] }\end{array}$ \\
\hline \multirow{2}{*}{ Male karate athletes } & 40 & $23 \pm 4$ & $181 \pm 6$ & $77 \pm 2$ \\
\cline { 2 - 5 } & & $(18-34)$ & $(172-195)$ & $(64-100)$ \\
\hline \multirow{2}{*}{$\begin{array}{c}\text { Female karate } \\
\text { athletes }\end{array}$} & 21 & $22 \pm 3$ & $168 \pm 5$ & $63 \pm 7$ \\
\cline { 2 - 5 } & & $(20-31)$ & $(157-175)$ & $(51-80)$ \\
\hline
\end{tabular}

The method of diagnostic survey questionnaire technique was used. Karate athletes anonymously filled out the individual author's questionnaire, consisting of questions about: gender, age, height, weight, laterality of the limbs, length of training experience, stage of karate training, severity of the trainee, frequency of other exercises, using protectors to avoid the injury, frequently recurring injuries, how many times during training or competition a particular part of the body was injured and about serious or permanent damage to the respondent's health [Appendix]. Survey results were collected and subjected to statistical analysis using Microsoft Excel and Statistica v.10 (StatSoft). The mean, standard deviation, minimum and maximum values, Mann U Whitney test and severity rates of specific indications were calculated. 


\section{Results}

Karate athletes were asked to indicate what type of protectors they use to prevent or minimize the risk of injury. In the first group, the most common protector was suspensor (protector of the genitals), used by $97 \%$ of the karate practitioners. Other often used protectors were leg - the tibia and feet (64\%), upper extremities and hands (43\%). Several athletes have also used a teeth guard (21\%) and knees protector (14\%). All questioned female athletes to minimize the risk of injury applied at most tibia and foot protectors (100\%), then -breasts protector (97\%), arms and hands (50\%), knee (21\%) and teeth (13\%). One of the women used additionally head protector. There was no person who did not use any protection during exercises (Table 2). Karate athletes were asked to indicate the most common injuries. In the study group prevailed: contusions (91\%), joint injuries (49\%) with a total number of 548 different types of injuries, especially related to the left foot (23\%) and right hand (19\%).

Table 2: The most commonly used protectors by males, females: the percentage of athletes who indicated the type of protection.

\begin{tabular}{|c|c|}
\hline Used Protectors -Males & $\begin{array}{c}\text { The Percentage of Males who use A } \\
\text { Particular type of Protectors }\end{array}$ \\
\hline Suspensor & $97 \%$ \\
\hline tibia and foot & $64 \%$ \\
\hline arms and hands & $43 \%$ \\
\hline Teeth & $21 \%$ \\
\hline knee joint & $14 \%$ \\
\hline Used Protectors & The Percentage of Females who use A \\
-Females & Particular type of Protectors \\
\hline tibia and foot & $100 \%$ \\
\hline Breasts & $97 \%$ \\
\hline arms and hands & $50 \%$ \\
\hline knee joint & $21 \%$ \\
\hline Teeth & $13 \%$ \\
\hline Head & $4 \%$ \\
\hline
\end{tabular}

Athletes reported also selected cases of torsion (7\%) and fracture $(7 \%)$. There was not statistically significant difference in the types of injuries between study groups except of injuries of the left foot $(p=0.002)$ and back $(p=0.017)$. The results are shown in Tables 3 \& 4. Subsequently, contestants were asked to indicate how many times during karate training particular part of the body was damaged and were asked about injuries that occurred in the body during the last year. The results are presented in Tables 5-7. In the first group most injuries were related to the left foot (13\%), right hand (12\%) and right foot (10\%). Reported cases of the right lower extremity injuries (hip injury, 9\%), chest, left hand, back (all at $8 \%$ ), right upper extremity (hip injury), face, right leg (muscleligamentous injury), left leg lower (joint sprain) (all at 5\%), left lower limb (ligamentous injury-muscular, 4\%), left upper limb (joint injury 3\%) and abdominal (3\%). Joint injuries were more frequent than muscle damages. There was no report of pelvis injury.
Table 3: The most common injuries in males and females the percentage of athletes who indicated the type of injury.

\begin{tabular}{|c|c|}
\hline $\begin{array}{c}\text { The type of Injury - } \\
\text { Males }\end{array}$ & $\begin{array}{c}\text { The Percentage of Males who Indicated } \\
\text { The Type of Injury }\end{array}$ \\
\hline Contusions & $93 \%$ \\
\hline joint injuries & $43 \%$ \\
\hline $\begin{array}{c}\text { muscle and fascia } \\
\text { damages }\end{array}$ & $29 \%$ \\
\hline Torsion & $7 \%$ \\
\hline Fracture & $7 \%$ \\
\hline $\begin{array}{c}\text { The type of Injury } \\
\text {-Females }\end{array}$ & $\begin{array}{c}\text { The Percentage of Females who } \\
\text { Indicated The Type of Injury }\end{array}$ \\
\hline Contusions & $96 \%$ \\
\hline joint injuries & $25 \%$ \\
\hline Torsions & $21 \%$ \\
\hline $\begin{array}{c}\text { muscle and fascia } \\
\text { damages }\end{array}$ & $13 \%$ \\
\hline
\end{tabular}

Note: From 2017-foot protectors and breasts protector are obligatory for women to participate in every one championships.

Table 4: The differences between most common injuries in males and females.

\begin{tabular}{|c|c|}
\hline Indicated Part of the Body Injured & Males vs females P \\
\hline Back & 0,017 \\
\hline right upper limb - joint trauma & 0,724 \\
\hline $\begin{array}{c}\text { right upper limb - ligamentous-muscular } \\
\text { trauma }\end{array}$ & 0,766 \\
\hline left upper limb - joint trauma & 0,292 \\
\hline left upper limb - ligamentous-muscular trauma & 0,219 \\
\hline right hand - joint trauma & 0,157 \\
\hline left hand - joint trauma & 0,135 \\
\hline right lower limb - joint trauma & \\
\hline right lower limb - ligamentous-muscular \\
trauma & 0,125 \\
\hline left lower limb - joint trauma & 0,342 \\
\hline left lower limb - ligamentous-muscular trauma & 0,325 \\
\hline right foot - joint trauma & 0,186 \\
\hline left foot - joint trauma & 0,002 \\
\hline pelvis - joint trauma & 0,355 \\
\hline Face & 0,397 \\
\hline Thorax & 0,869 \\
\hline abdomen & 0,964 \\
\hline
\end{tabular}

There was no person who does not suffer any injury of the mentioned. The results are shown in Table 5. In the second group, among women while practicing karate the most commonly reported injuries were related to the: right foot (15\%), right hand (14\%) and left foot (12\%). Reported cases of right upper extremity injury (injury to the joint $8 \%$ ), left hand (7\%), chest, face (7\% each), right arm (joint sprain, 6\%), left upper extremity (hip injury 5\%), left lower limb (hip trauma - 4\%), abdominal (4\%), back (3\%), right left leg (ligamentous-muscular injury 2\%), and left and right 
upper limb (ligamentous-muscular injury 1\%). Joint injuries were more frequent than muscle ones. Responses are shown in Table 6. Respondents suffered a total of 548 different types of injuries - 186 injuries among women and 362 injuries in men. Mean rate of injury for one person among men were: 0.78 , in which the right hand was: 1.64, left hand was: 1.0, right foot was: 1.36 , left foot was: 1.79 ; head was: 0.64 . For women, the mean rate of injury for one person was: 0.62 , including the right hand: 1.52 , left hand: 0.74 , right foot: 1.59 , left foot: 1.25 , head 0,74 . In the past year in the group of males, $43 \%$ of them did not suffer injury. Most injuries underwent were right hand (21\%), left lower limb (21\%) and chest (14\%). Reported isolate cases of injury to face, left hand, right leg, foot and back (all at 7\%) (Table 7). In the second group, in the last year 8\% of karate kyokushin female athletes did not suffer any injury. Similarly, as in male group, the most occurring was the right hand injury (42\%). Subsequently - right foot (29\%), right lower limb (21\%), face (17\%), left lower limb (17\%), left foot (17\%). There were several cases of abdominal trauma (13\%), left hand (13\%), right arm (4\%), chest (4\%) and back injury (8\%). Responses are shown in Table 8.

Table 5: The most damaged part of the body in males: number of males who have suffered trauma (N), the mean incidence of injury to one karate athlete, the percentage of males who identified the part of the body.

\begin{tabular}{|c|c|c|}
\hline Indicated Part of the Body - Males & $\begin{array}{l}\text { The mean Incidence of Injury on } \\
1 \text { Person }\end{array}$ & $\begin{array}{l}\text { The Percentage of Indicated Part of the Body in } \\
\text { the Total Number of Reported Injuries }\end{array}$ \\
\hline Back & 1,00 & $8 \%$ \\
\hline right upper limb - joint trauma & 0,64 & $5 \%$ \\
\hline right upper limb - ligamentous-muscular trauma & 0,14 & $1 \%$ \\
\hline left upper limb - joint trauma & 0,36 & $3 \%$ \\
\hline left upper limb - ligamentous-muscular trauma & 0,14 & $1 \%$ \\
\hline right hand - joint trauma & 1,64 & $12 \%$ \\
\hline left hand - joint trauma & 1,00 & $8 \%$ \\
\hline right lower limb - joint trauma & 1,21 & $9 \%$ \\
\hline right lower limb - ligamentous-muscular trauma & 0,64 & $5 \%$ \\
\hline left lower limb - joint trauma & 0,71 & $5 \%$ \\
\hline left lower limb - ligamentous-muscular trauma & 0,57 & $4 \%$ \\
\hline right foot - joint trauma & 1,36 & $10 \%$ \\
\hline left foot - joint trauma & 1,79 & $13 \%$ \\
\hline pelvis - joint trauma & 0,00 & $0 \%$ \\
\hline Face & 0,64 & $5 \%$ \\
\hline Thorax & 1,07 & $8 \%$ \\
\hline abdomen & 0,35 & $3 \%$ \\
\hline
\end{tabular}

Table 6: The most damaged part of the body in females: number of females who have suffered trauma (N), the mean incidence of injury to one karate athlete, the percentage of females who identified the part of the body.

\begin{tabular}{|c|c|c|}
\hline $\begin{array}{c}\text { Indicated Art of the body - } \\
\text { Females }\end{array}$ & $\begin{array}{c}\text { The mean Incidence of Injury on } \\
\mathbf{1} \text { Person }\end{array}$ & $\begin{array}{c}\text { The Percentage of Indicated Part of The Body in } \\
\text { the Total Number of Reported Injuries }\end{array}$ \\
\hline Back & 0,37 & $3 \%$ \\
\hline right upper limb - joint trauma & 0,89 & $8 \%$ \\
\hline right upper limb - ligamentous-muscular trauma & 0,07 & $5 \%$ \\
\hline left upper limb - joint trauma & 0,52 & $1 \%$ \\
\hline left upper limb - ligamentous-muscular trauma & 0,07 & $14 \%$ \\
\hline right hand - joint trauma & 1,52 & $7 \%$ \\
\hline left hand - joint trauma & 0,74 & $6 \%$ \\
\hline right lower limb - joint trauma & 0,67 & $2 \%$ \\
\hline right lower limb - ligamentous-muscular trauma & 0,22 & \\
\hline
\end{tabular}




\begin{tabular}{|c|c|c|}
\hline left lower limb - joint trauma & 0,41 & $4 \%$ \\
\hline left lower limb - ligamentous-muscular trauma & 0,19 & $2 \%$ \\
\hline right foot - joint trauma & 1,59 & $12 \%$ \\
\hline left foot - joint trauma & 0,19 & $2 \%$ \\
\hline pelvis - joint trauma & 0,74 & $7 \%$ \\
\hline Face & 0,7 & $7 \%$ \\
\hline Thorax & 0,44 & $4 \%$ \\
\hline
\end{tabular}

Table 7: The most damaged part of the body in the last year among males: number $(\mathrm{N})$, the percentage of males who identified the part of the body.

\begin{tabular}{|c|c|}
\hline $\begin{array}{c}\text { Indicated part of the Body - } \\
\text { Males }\end{array}$ & The Percentage of Males in the Group who Indicated Particular Part of the Body \\
\hline Face & $7 \%$ \\
\hline right hand & $21 \%$ \\
\hline left hand & $7 \%$ \\
\hline left lower limb & $21 \%$ \\
\hline right lower limb & $7 \%$ \\
\hline left foot & $7 \%$ \\
\hline right foot & $7 \%$ \\
\hline left upper limb & $0 \%$ \\
\hline right upper limb & $0 \%$ \\
\hline Abdomen & $0 \%$ \\
\hline Pelvis & $0 \%$ \\
\hline lack of the injury in the past year & $43 \%$ \\
\hline Thorax & $14 \%$ \\
\hline Back & $7 \%$ \\
\hline Face & 0,74 \\
\hline Thorax & 0,7 \\
\hline Abdomen & 0,44 \\
\hline
\end{tabular}

Table 8: The most damaged part of the body in the last year among females: number $(\mathrm{N})$, the percentage of females who identified the part of the body.

\begin{tabular}{|c|l|}
\hline $\begin{array}{c}\text { Indicated part of the Body - } \\
\text { Females }\end{array}$ & The Percentage of Females in the Group who Indicated Particular Part of the Body \\
\hline Face & $17 \%$ \\
\hline right hand & $42 \%$ \\
\hline left hand & $13 \%$ \\
\hline left lower limb & $17 \%$ \\
\hline right lower limb & $21 \%$ \\
\hline left foot & $17 \%$ \\
\hline right foot & $29 \%$ \\
\hline left upper limb & $4 \%$ \\
\hline right upper limb & $8 \%$ \\
\hline
\end{tabular}




\begin{tabular}{|c|c|}
\hline abdomen & $13 \%$ \\
\hline Pelvis & $0 \%$ \\
\hline lack of the injury in the past year & $8 \%$ \\
\hline Thorax & $4 \%$ \\
\hline Back & $8 \%$ \\
\hline
\end{tabular}

Lastly, athletes were questioned whether during training they encountered with serious or permanent damage to the health Serious and permanent injury occurred rarely. In the first group experienced them $35 \%$ of males and in the second group it was $12 \%$ of females. In the first group $65 \%$ of men during long-term training were not encounter with a severe or permanent damage to the health. The other karate athletes mentioned: bone fractures tibia and nose, a concussion ( 5 years ago), damage to the ligaments of the knee joint and incompetent use of cooling spray resulting in necrosis of the skin. In the same group, $88 \%$ of females have no experienced serious or permanent injury. Other women from the first group mentioned: fractures-of the forearm, metacarpal bones and knee ligament damage. Respondents completing the survey were asked to answer questions about the frequently recurring injuries, how many times during training or competition a particular part of the body was injured without their mechanism of occurrence. The results are shown in Table 9.

Table 9: The most indicated severe or permanent damage to the health experienced during exercises, of the males and females: number $(\mathrm{N})$, the percentage of athletes who indicated an injury.

\begin{tabular}{|c|c|}
\hline Indicated Severe or Permanent Damage to Health by Male Karate Athletes & The Percent of Males who indicated The Type of Injury \\
\hline concussion (5 years ago) & \\
\hline nasal fracture & $7 \%$ \\
\hline necrosis of the skin after application of cooling spray & $7 \%$ \\
\hline open fracture of the tibia & $7 \%$ \\
\hline rapture of the ligaments in the knee joint & $7 \%$ \\
\hline Lack & The percent of females who indicated The type of injury \\
\hline Indicated severe or permanent damage to health by female karate athletes & $4 \%$ \\
\hline forearm fracture & \\
\hline fracture metacarpal joint & $4 \%$ \\
\hline rapture of the ligaments in the knee & $8 \%$ \\
\hline
\end{tabular}

\section{Discussion}

Arriaza and Leyes [3] analyzed the injuries sustained by athletes training karate: shotokan, shito-ryu, goju-ryu and wadoryu - taking part in three consecutive World Championships. The mean value of the injuries was at level 157.03/1000 competitors. Authors reported 891 injuries. The most common injuries were contusions of the large muscle groups (50.3\%), facial traumas resulting in bleeding from nose (16.2\%), cuts and abrasions $(13.7 \%)$ and twisting of ligaments (3.5\%). There were 796 (89.3\%) minor injuries, 70 (7.9\%) moderate and 25 (2.8\%) severe injuries. Severe cases of injuries resulted in concussion, internal organs damages, third-degree sprains, eye injuries and various types of fractures. Most injuries were related to the face $(72.5 \%)$, head (11.6\%) and lower limb (6.4\%). In our study in groups of karate kyokushin athletes strongly dominated minor injuries as contusions and joint injuries within hands and feet. The overall proportion of severe injuries was lower than in Arriaza and Leyers study.

These differences may be since athletes analyzed by the Arriaza and Leyers took part in the World Karate Championships (high level of competitors), while our competitors were taking part in the Polish and European Championships. Differences may be also related to the dissimilarities occurring between each style of karate. In the kyokushin style up to year 2017-foot protectors were not obligatory for women and only obligatory protectors were breasts protectors for women and suspensors for men. The authors emphasize that competitive karate is associated with a relatively high injury rate and note that cases of severe injuries were rare what is compatible with our study. Destombe et al. [5] analyzed the injuries sustained by the 186 French karate athletes for a period of 1 year. The study gropup consists of karatekas from three karate clubs in Brest, France but the author did not mention the style of karate. Total number of injuries was 83 (63 during trainings, 20 during competitions), average injuries stood at 44.6/100 players. The most common injuries were hematomas (53\%), twisting (19\%), muscle injuries (7\%), fractures (7\%), cuts and abrasions (7\%). Predominated limb injuries were the upper $(28.9 \%)$ and lower (35\%), followed by head (26.5\%) and trunk (9.6\%) injuries. Authors stress that injury rate increases with time spent on trainings, rank of each competitor and years of practice what is 
similar to our study. Destombe et al. also emphasize that serious injuries in karate are rare. Minor injuries of the upper and lower limbs are dominating, what is compatible with our findings. Zazryn et al. [6] in turn, studied the incidence of injuries among professional athletes training kickboxing for a period of 16 years. Total number of injuries was 382, mean value of injuries stood at 109.7/1000 competitors. The most common injuries were superficial ones like bruises, lacerations and abrasions (over 64\%). Predominated head, neck, face (51.6\%) and lower limbs (39.8\%) injuries, the lower leg (23.3\%), face (19.4\%) and intracranial injuries (17.2\%).

The nature of kickboxing where kicking the opponent is the major movement and head is a prime object was associated with the distributions of body regions mostly injured by participants. The nature of kickboxing, whereby kicking the opponent is the prime movement and the head a prime target, is reflected in the distributions of body regions most commonly injured by participants. Therefore, the results obtained by authors differed from results received in karate kyokushin athletes (differences between karate kyokushin and kickboxing style). Gartland et al. [7] studied the incidence of injuries in muay thai kickboxing athletes. The survey was conducted among 152 people. Mean value of injuries stood at 13.5/1000 recreational competitors' athletes (amateurs) and 2.79/1000 professional athletes. The most suffered injuries were bruises, lacerations and abrasions. Among the amateurs dominated injuries to the lower limbs (75\%), trunk $(15.9 \%)$ and upper extremities (6.8\%). Head injuries accounted for $2.3 \%$ of all injuries.

Among professional athlete's lower limb injuries (53\%) also predominated. More often they experienced trauma to the head and trunk. The most frequently occurring injuries were: bruises, sprains, cuts and abrasions. Authors highlight that different martial arts are associated with particular injury pattern which may explain the differences in percentage distribution of injuries between muay thai kickboxers and karate kyokushin practitioners. However, worth noting is fact that, according to the authors, karate is linked to the traumas within the lower extremities, as it can be seen in our study. Kazemi et al. [8] analyzed the injuries suffered by athletes training taekwondo for a period of 9 years. Average injuries stood at 16.18/100 athletes. Predominated head injuries (19\%), foot injuries (16\%) and thigh (9\%). Minor traumas as: contusions (36\%), sprains (19\%) and muscle strains (15\%) were the most common. Differences between Kazemi et al and our study occurred in the distribution of rates and the leading locations of injuries.

Nevertheless, according to the authors, the most commonly reported injuries were bruises, injuries of joints and muscles, which is similar to our results. Kujala et al. [9] analyzed 54186 sports injuries sustained by judo, karate, football, ice hockey, basketball and volleyball players in the years 1987-1991. Average injuries stood at 142/1000 of karate athletes, 117/1000 of judo competitors, 94/1000 of hockey players, 89/1000 among football players, $88 / 1000$ among basketball players and $60 / 1000$ of the volleyball players. In team games $46-59 \%$ of injuries happen during competitions and tournaments, while in martial arts the figure was $70 \%$. Injuries typical for each discipline predominated. Fractures and teeth injuries were the most common among players of hockey and karate, lower extremity injuries among football and volleyball players and upper extremity injuries in judo. Sprains, muscle injuries and contusions were the most common types of injuries. The most predominant areas of the injury among karate athletes, according to the authors' injury were lower limbs (37.3\%) especially: knee (11\%) and foot (10.7\%), and upper limbs (26.3\%) - fingers (9.3\%). Other traumatic sites (36.3\%) were head and neck (10.9\%). Mostly injuries (sprains, strains, bruises, fractures) were related to the striking surfaces in karate-hand and feet joints, what is compatible with our study findings.

Zetaruk et al. [10] investigated the incidence of injuries among the 263 athletes trained martial arts. The survey was conducted among athletes training: karate shotokan (114 individuals), aikido (47 people), taekwon-do (49 athletes), kung fu (39 athletes) and tai chi (14 individuals). Most injuries were related to the athletes practicing taekwon-do (59\%), aikido (51\%) and kung fu (38\%). The least frequent injuries applied to karate shotokan athletes (30\%) and tai chi (14\%). According to the authors karate shotokan athletes suffered 114 injuries, among which the lower extremity (22.8\%), upper extremity (16.7\%), trunk (14.9\%) and head, neck injuries (9.6\%) were dominating. The areas of suffered injuries in karate shotokan athletes are consistent with parts of the body that have been injured in karate kyokushin individuals even despite the differences in shotokan karate protector's usage (obligatory to compete are tibia and foot, hands protectors for athletes and breast protectors for women and suspensor for men).

Also, Vitale et al. [13] investigated foot anatomy, anthropometric measures, and other background factors and information as possible risk factors of injury in barefoot athletes practicing judo, karate, kung fu, Thai boxing, or aikido. The results of 130 subjects showed that most of the athletes (53.8\%) did not sustain lower lib injuries, $19.2 \%$ reported an overuse injury and $27.0 \%$ suffered an acute injury. No significant differences were observed in the injury rates in relation to style and kind of martial art. Interesting and worth mentioning was the fact that in this study older and heavier martial artist, performing more hours of barefoot training, were at higher risk of acute and overuse injury. This aspect has not been addressed in authors' study and requires further research on a larger study group divided into weight categories in the future. Other study shows that even athletes who taking part in kata tournaments (without fighting) are suffering form and overuse injury with the occurrence of pain in the joints of the lower extremities and lumbar spine from performing the basic stances [17]. 
Over the years a reduction in average number of injuries in martial arts [11,12], including several acute injuries as concussions to muscle and tendon ones, has been observed. Perhaps, it is due to the widespread use of protectors, greater awareness in the treatment area, prevention of damage and stricter enforcement of the competitions. But it can also be caused by insufficient data. As Thomas et al. [18] indicate that studies need to adopt one injury definition, one data-collection form, and collect comprehensive data for each study for both training and competitions. More data are needed to measure the effect of weight, age and experience on injuries, rates and types of injury during training, and for competitors with high injury rates. RCTs are needed of interventions such as training and feedback of performance data to reduce injury rates. The reduction in average number of injuries can be also caused by the changes to the safety regulations (i.e. foot protectors in females) by members of the approvals board and medical ethics $[14,15]$. The Council for Medical Ethics discourages doctors from accepting to act as ringside doctor for combat sports that permit knockouts or participating in approvals or appeals boards for such events because these types of assignments in their opinion may violate the general duty of doctors to protect human health [15].

Moreover, finding of this study considering other research presented above are justifying a recommendation for coaches to differ a training or accept a physiotherapist in order to prevent injuries due to overload of ligaments and muscles as it is in other professional sports. Martial arts did not emphasize use of rejuvenation treatment for athletes as it is on other professional sports, maybe due to insufficient founding in comparison to for example football. Polish karate kyokushin athletes use all the rejuvenation treatment individually on their own [16]. Karate clubs do not provide such treatment. This study reveals some information about competitive athletes and those statistics should not be extrapolated toward all practitioners. As in many other martial arts, people are more concern about their health and tend to avoid injuries [19]. Such risk and special attention should be given to those, who prepare for competitions only.

\section{Conclusion}

a. Most of athletes are willing to use protection of central parts and striking surfaces.

b. Women athletes are slightly more prone to use protective equipment than male athletes.

c. Injuries were more frequent among distal part of the body (hands and feet) than the central ones. d. Males suffers more back and foot injuries than women.

\section{References}

1. Terry ChM (2006) The Martial Arts Physical Medicine and Rehabilitation Clinics of North America 17: 645-676.

2. Gloc D, Plewa M, Nowak Z (2012) The effects of kyokushin karate training on the anthropometry and body composition of advanced female and male practitioners. J Combat Sports Martial Arts 1(2): 63-71.

3. Arriaza R, Leyes M (2005) Injury profile in competitive karate: Prospective analysis of three consecutive World Karate Championships. Knee Surg Sports Traumatol Arthrosc 13: 603-607.

4. Nishime RS (2007) Martial Arts Sports Medicine: Current Issues and Competition Event Coverage. Current Sports Med Rep 6(3): 162-169.

5. Destombe C, Lejeune L, Guillodo Y, Roudaut A, Jousse S, et al. (2006) Incidence and nature of karate injuries. Joint Bone Spine 73(2): 182-188.

6. Zazryn TR, Finch CF, McCrory P (2003) A 16-year study of injuries to professional kickboxers in the state of Victoria, Australia. Br J Sports Med 37(5): 448-451.

7. Gartland S, Malik MHA, Lovell ME (2001) Injury and injury rates in Muay Thai kick boxing. Br J Sports Med 35(5): 308-313.

8. Kazemi M, Chudolinski A, Turgeon M, Simon A, Ho E, et al. (2009) Nineyear longitudinal retrospective study of Taekwondo injuries. J Can Chiropr Assoc 53(4): 272-281.

9. Kujala UM, Taimela S, Antti Poika I, Orava S, Tuominen R, et al. (1995) Acute injuries in soccer, ice hockey, volleyball, basketball, judo, and karate: analysis of national registry data. Br J Sports Med 311(7018): 1465-1468.

10.Zetaruk MN, Violán MA, Zurakowski D, Micheli LJ (2005) Injuries in martial arts: a comparison of five styles. Br J Sports Med 39(1): 29-33.

11. Burke DT, Barfoot K, Bryant S, Schneider JC, Kim HJ, et al. (2003) Effect of implementation of safety measures in tae kwon do competition. $\mathrm{Br}$ Sports Med 37(5): 401-404.

12. Critchley GR, Mannion S, Meredith C (1999) Injury rates in Shotokan karate. Br Sports Med 33(3): 174-177.

13. Vitale JA, Bassani T, Galbusera F, Bianchi A, Martinelli N (2018) Injury rates in martial arts athletes and predictive risk factors for lower limb injuries. J Sports Med Phys Fitness 58(9): 1296-1303.

14. Čierna D, Barrientos M, Agrasar C, Arriaza R (2018) Epidemiology of injuries in juniors participating in top-level karate competition: a prospective cohort study. Br J Sports Med 52(11): 730-734.

15. Hytten K, Tønsaker SK (2017) Medical ethics in combat sports that permit knockouts. Tidsskr Nor Laegeforen 31(17): 137.

16. Piejko L, Gloc D, Ryngier P (2015) The therapeutic procedures of injuries female and male seniors participating in XXXIX Polish Karate Kyokushin Championships. Scientific Review of Physical Culture 5(2): 88-96.

17. Lisowska A, Ogurkowska MB, Gabryelski J (2017) Analysis of the occurrence of musculoskeletal pain in Shotokan karate kata athletes. J Combat Sports Martial Arts 8: 77-82.

18. Thomas RE, Ornstein J (2018) Injuries in karate: systematic review. Phys Sportsmed 46(3): 279-303.

19. Wąsik J, Wójcik A (2017) Health in the context of martial arts practice. Physical Activity Review 5: 91-94. 
ISSN: 2574-1241

DOI: 10.26717/BJSTR.2019.15.002653

Laura Piejko. Biomed J Sci \& Tech Res

(c) (i) This work is licensed under Creative

Submission Link: https://biomedres.us/submit-manuscript.php

$\begin{array}{ll}\text { BIOMEDICAL } & \text { Assets of Publishing with us } \\ \text { RESEARCHES } & \text { - Global archiving of articles } \\ \text { - Immediate, unrestricted online access } \\ \text { - Rttps://biomedres.us/ }\end{array}$

